\title{
William Whiston, suur veeuputus ja kohutav spektaakel
}

\author{
Roomet Jakapi
}

\begin{abstract}
Teesid
Artiklis tutvustatakse inglise matemaatiku, astronoomi ja teoloogi William Whistoni (1667-1752) teaduslik-religioosset mõtteviisi. W. Whistoni ideed on ilmekaks näiteks teadusliku ja religioosse mõtlemise tihedast vastastikusest seotusest ja läbipõimumisest varasemal uusajal. Keskse vaatluse all on W. Whistoni teos Loomuliku ja ilmutusreligiooni astronoomilised printsiibid (1717). W. Whiston püüdis kindlaks määrata suure veeuputus aja. Tema väitel on Maa olnud meile tuttavas olekus $6000-7000$ aastat ja suurest veeuputusest on möödunud 5000 aastat. Ta väitis, et veeuputuse põhjustas 1680/1. aasta komeedi lähenemine maale. Kõrvutades piibellikke põrgukirjeldusi tollase teadusliku evidentsiga komeetide kohta, tegi W. Whiston loogilise teaduslik-teoloogilise järelduse, et põrgu saab asuma komeedi pinnal või atmosfääris.
\end{abstract}

Märksõnad: Boyle, Newton, religioon, teaduse ajalugu, Whiston

William Whiston (1667-1752) - inglise teoloog, matemaatik ja astronoom - on märkimisväärne kuju teaduse, religiooni ja võib-olla ka filosoofia ajaloos. Käesolevas artiklis püüan lühidalt iseloomustada W. Whistoni mõtteviisi, keskendudes teaduslikele ja religioossetele aspektidele, mis on mitmetes tema tuntumates teostes teineteisega tihedasti seotud.

W. Whistoni esimene ja ilmselt ka mõjukaim teos Uus teooria Maa kohta ${ }^{1}$ ilmus aastal 1696. Selles teoses püüdis ta näidata, et Piiblis sisalduv loomislugu, suure veeuputuse lugu jts on tõesed. W. Whiston oli seisukohal, et Piibel annab sääraste sündmuste kohta tõese ajaloolise kirjelduse, kuid see ei ole "peen ja filosoofilne", st teaduslik käsitlus ega seletus, kuid tema arusaama kohaselt on Piiblis kirjas tõde Maa tekkimise ja ajaloo kohta ning seda tõde on võimalik kinnitada ja käsitleda ka teaduslikult. Ta lükkas tagasi Thomas Burneti allegoorilise piiblitõlgenduse, ${ }^{2}$ esinedes korraga nii eksegeedi kui ka teadlase rollis. Võib öelda, et ta oli Isaac Newtoni jälgedes käiv teadlane-teoloog ja selleks ta ka jäi (Force 1985).

http://haldjas.folklore.ee/tagused/nr30/jakapi.pdf 


\section{Roomet Jakapi}

1702. aastal sai W. Whistonist Sir Isaac Newtoni (1643-1727) järglane Lucas'i matemaatikaprofessori toolil Cambridge'i Ülikoolis. I. Newton ise valis ta seda ametiposti täitma. Sellele vaatamata ei saanud W. Whistonist kunagi autoriteetse, juhtivaid teadusemeelseid mõtlejaid koondava Kuningliku Seltsi (Royal Society) liiget.

Tärkava ja areneva teadusliku mõtteviisi liit ja põimumine religiooniga oli igati loomulik. Nagu hästi teada, pani Robert Boyle (1627-1691) - vaga kristlane ja silmapaistev uue eksperimentaalse teaduse eestvedaja - aluse loengute sarjale, mida tuntaksegi Boyle'i loengutena. Neis loengutes, mida peeti aastail 1692-1732, tegelesid tollased juhtivad akadeemilised isikud ja mõtlejad loomuliku religiooni ja ilmutusreligiooni kaitsmisega ateismi vastu. Need mõisted vajavad ehk põgusat lahtiseletamist. Jumala eksistents ja atribuudid ning inimhinge surematus kuulusid tollal üldiselt aktsepteeritud seisukoha järgi mõistusega avastatavate ja tõestatavate tõdede hulka. Et mõistuspärane (mõistuslik) oli ühtlasi loomulik, ja vastupidi, loomulik oli mõistuspärane, nimetati seda osa religioonist vastavalt mõistuse- ehk loomulikuks religiooniks. Väidetavalt hõlmab aga kristlus endas ka sääraseid tõdesid, mis on üle mõistuse (above reason) - need on meile teada jumaliku ilmutuse

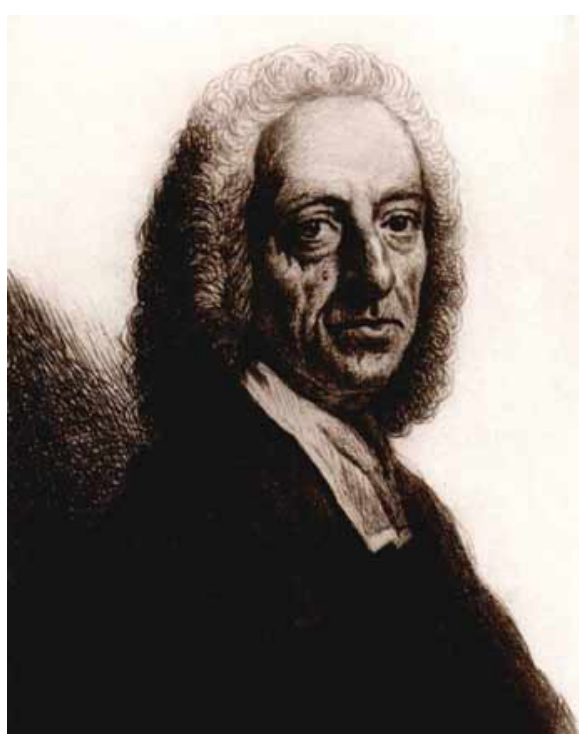

William Whiston (1667-1752). kaudu, ent jäävad sellisenagi seletamatuks ja salapäraseks. Näiteks pärispatu müstiline edasikandumine põlvest põlve, Jumala armu toimimine siin ilmas, inimese hinges - need on mõistusega äraseletamatud tõed, mida ometi tuleb uskuda, tuginedes veendumusele, et need tõed on meile pühakirjas ilmutanud Jumal ise. Viimaste hulka kuulub ka õpetus Pühast Kolmainust.

W. Whiston esines R. Boyle'i loengute sarjas aastal 1707. Tema kaastöö sellele suurejoonelisele projektile avaldati pealkirja Pühakirja prohveteeringute täideminek 
all. Niisiis kuulus ta vähemasti neil aastail vägagi lugupeetud ja tunnustatud mõtlejate seltskonda.

Paraku sai temast hereetik. Nii nagu I. Newtongi, ütles W. Whiston lahti Athanasiuse usutunnistuses formuleeritud Kolmainu-õpetusest. Erinevalt Isaac Newtonist söandas W. Whiston oma antitrinitaarseid vaateid ka avalikult tunnistada ja õige pea teenis ta selle eest ära valusa karistuse - aastal 1710 aeti ta ülikoolist minema. I. Newton oli märksa ettevaatlikum ja säilitas hea reputatsiooni. Siinkohal peab toonitama, et üksnes kolmainu eitamine ei tä-

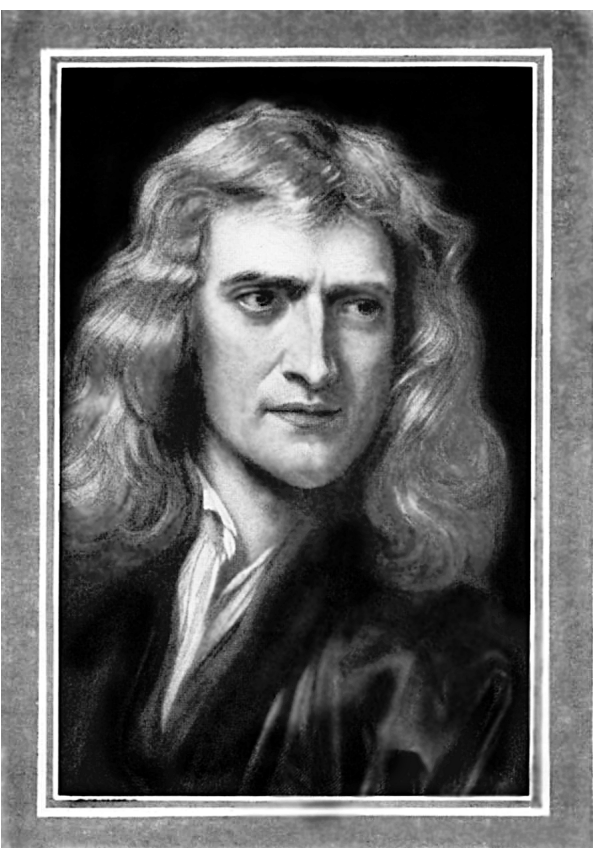

Sir Isaac Newton (1643-1727). hendanud Jumala olemasolu või muude oluliste kristlike tõdede eitamist. Kõige sagedasem argument, mis kolmainu-õpetuse vastu esitati, oli, et see õpetus ei pärine Piiblist ja järelikult ei ole osa jumalikust ilmutusest. Pärast neid dramaatilisi sündmusi kolis W. Whiston Londonisse, kus ta pidas mõjukaid avalikke loenguid nii religioossetel kui ka teaduslikel teemadel ning avaldas järgnenud aastakümnete vältel ka rea asjassepuutuvaid teoseid.

W. Whistoni üldarusaamad Jumala, inimese ja maailma kohta on oma ajastu kontekstis tavapärased. Varauusaegse ${ }^{3}$ teaduse või õigemini loodusfilosoofia (philosophia naturalis) esindajad, moodsa loodusteaduse alusepanijad, olid reeglina religioossed inimesed. Nad elasid, mõtlesid ja tegutsesid paljuski piibellike uskumuste ja kirikudogmade vormitud intellektuaalses maailmas. I. Newton, R. Boyle ja teised prominentsed Kuningliku Seltsi liikmed nägid loodusfilosoofias kristliku usu liitlast ja kinnitajat, mitte vastast ega õõnestajat. Sama võib öelda W. Whistoni kohta. 


\section{Roomet Jakapi}

Tollal leidus ka mitmeid vabamõtlejaid (nt Charles Blount ja Anthony Collins), kes söandasid esitada piiblilugudele vastuväiteid, neid lugusid naeruvääristada ja koguni vaidlustada Piibli jumalikku päritolu ja autoriteeti. Nende vastuväiteid ja kriitikat võeti arvesse ja püüti kummutada. Aga üldiselt nägi vaimueliit vabamõtlejates pigem lahmivaid skandaalijanulisi dissidente ning kuritahtlikke religiooni ja moraali õonestajaid kui tõsiseid mõtlejaid või asjatundjaid. Enamikule oli Piibel endiselt Jumala Sõna, Looja ilmutus ja esmane tõeallikas.

Reeglina uskusid tollased "loodusfilosoofid", et maailm on loo$d u d$ ja paljude arvates vähem kui 10000 aasta eest. ${ }^{4}$ Samuti usuti, et inimene on loodud. Usuti, et kehaline surm ei ole inimese personaalse eksistentsi lõpp. Rõhutagem, et 17. sajandil ja 18. sajandi esimesel poolel oli endiselt täiesti loomulik ja normaalne uskuda tõsiselt surnute ülestõusmisesse ja viimse kohtupäeva saabumisse. Samuti jääb mulje, et reeglina lootsid tollased silmapaistvad mõtlejad tõepoolest pälvida igavese elu ja õnne tulevases taevariigis. Igasuguse surmajärgse elu eitamine - radikaalne mortalism oli üsna harv nähtus, seda isegi vabamõtlejate kirjutistes.

Niisiis pole ime, et I. Newton, W. Whiston ja R. Boyle nägid üksjagu vaeva, et kohandada oma teaduslikke avastusi ja arutlusi fun-

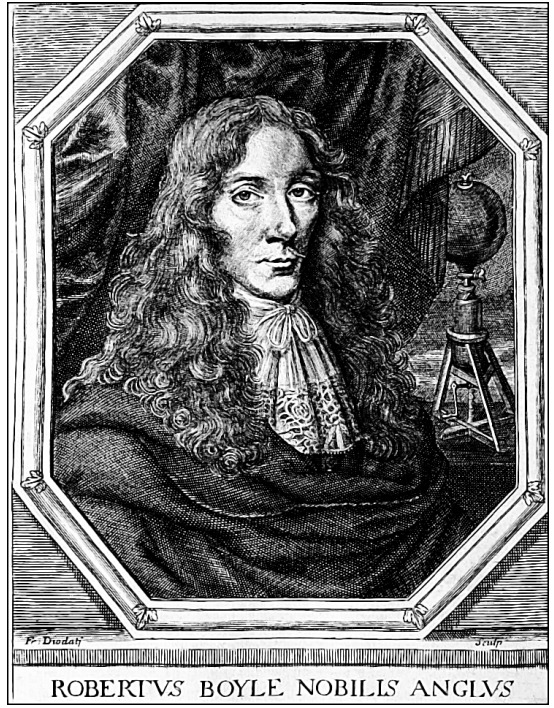

Robert Boyle (1627-1691). damentaalsete religioossete veendumuste ja üldise religioosse mõtteraamistikuga. ${ }^{5}$ Samas ei tähenda see, et Inglismaal tegutsenud loodusfilosoofid tunnistanuks kuulekalt anglikaani kiriku kõiki õpetusi või "usuartikleid". Nagu juba mainitud, pooldasid mõned (salaja) heterodoksseid vaateid ühe või teise konkreetse õpetuse suhtes. Igatahes oli varasema uusaja loodusfilosoofia õige mitmes aspektis lähedalt seotud religioossete küsimustega, mida võeti väga tõsiselt.

W. Whistoni mõtlemine on heaks näiteks sellest, mida on nimetatud njuutonliku teadu- 
se ja religiooni "vastastikuseks lähenemiseks" ('rapprochement' between Newtonian science and religion) (Force 1985: xxi, 2, 10). W. Whistoni teos Loomuliku ja ilmutusreligiooni astronoomilised printsiibid (Whiston 1717) sobib hästi illustreerima äsjanimetatud nähtust ideede ajaloos. Juba raamatu pealkiri on tähelepanuväärne ja kõnekas. Tänapäeval peetakse astronoomiat loodusteaduse haruks ja seeläbi vastandatakse seda rohkem või vähem teravalt niisugustele tegevusaladele või valdkondadele nagu religioon või nn pseudoteadused. Arvestades teadusliku mõtlemise autoriteeti tänapäeva lääne maailmas ja religiooni mõningast tõrjutust (eriti Euroopas), tundub, et astronoomia ja religiooni sisulise kokkusegamise püüdlusi ei saa päris tõsiselt võtta. Pigem tuleks neid valdkondi lahus hoida. William Whistoni ajal olid lood mõnevõrra teisiti. Tema raamatus on teadus ja religioon laulatatud enam-vähem õnnelikku abiellu. Järgnevalt visandan paar ilmekat stseeni sellest abielust.

Raamatu viis esimest osa kirjeldavad "maailmasüsteemi" Isaac Newtoni mehaanika printsiipide kohaselt. Teaduse ja religiooni vastastikune lähenemine saab ilmseks raamatu 6. ja 7. osas, mis tegelevad vastavalt loomuliku religiooni oluliste printsiipide ja jumaliku ilmutuse oluliste printsiipidega. Neist esimesed printsiibid, nimelt inimhingede mittemateriaalsus ja surematus, samuti Jumala eksistents ja atribuudid, tuletatakse kõik sestsamast maailmasüsteemist. Nii näiteks järeldab W. Whiston, et maailm ei ole eksisteerinud igavesti: selle lõi Jumal. Jumala kõikvõimas vägi lõi universumi mateeria eimillestki (Whiston 1717: 108). Jumal on igavene olend, kes eksisteerib ilma igasuguse põhjuse või alguseta (Whiston 1717: 110). Jumal on vaba toimija (Whiston 1717: 114). Ta on intelligentne ja kõiketeadev (Whiston 1717: 116), kõikjal kohalolev (Whiston 1717: 120 ) jne. Muu hulgas seletab W. Whiston Jumala suhet loodud füüsilise maailmaga. Jumal toimib füüsilises maailmas mittemehaaniliste vägede abil. Kui Jumal maailmas lakkamatult ei toimiks, laguneks kogu süsteem laiali, aatomiteks (vt Whiston 1717: $111 \mathrm{jj}$ ). William Whiston kirjutab:

Ülim Jumal, universumi Looja ja Valitseja, on oma loomu ja substantsi poolest immateriaalne. See on otsene järeldus tõelisest maailmasüsteemist, millest nähtub, et Jumal, see ainus gravitatsiooniväe looja, toimib ja on kohal kõigi tahkete kehade sisimates osades, ja koguni nii, et ta on ühtviisi ja vältimatult kohal ja toimib nii nendes tahkete kehade sisimates osades kui ka kõikides tühja ruumi punktides ning lisaks, et see 


\section{Roomet Jakapi}

toime kõigi kehade peale ei sarnane materiaalse ja mehaanilise impulsiga, mille mõju on pinnapealne, vaid läbistab kehi endid ning põhjustab kõikjal gravitatsiooni [---] (Whiston 1717: 123).

Niisiis on Jumal - immateriaalne vaim - kohal või peitub kõigis kehades (nagu ka tühjas ruumis) ja põhjustab gravitatsiooni. Iseenesest on see ju traditsioonilise arusaama, et Jumal on kõikjal kohalolev, fü̈̈sikalis-teoloogiline väljendus.

Raamatu 7. osas keskendutakse jumaliku ilmutusega seonduvale. Muu hulgas kuulub siia arutelu maailma loomise ja suure veeuputuse üle.

William Whiston on enim tuntud selle poolest, mida ta on kirjutanud komeetide kohta. Nimelt omistas ta komeetidele maailma arenguloos väga olulise rolli. Näiteks oli ta arvamusel, et praegune Maa loodi algselt komeedina, seejärel aga muutis Jumal selle komeedi planeediks. W. Whiston interpreteeris 1 . Moosese raamatu algust nii, et see kaos, millest Maa loodi, ei ole midagi muud kui komeedi atmosfäär (Whiston 1717: 139). Nii nagu Edmund Halley (1656-1742) enne teda, püüdis ka W. Whiston kindlaks teha suure veeuputuse (vt 1 Mo: 6-8) füüsikalist põhjust. Mõlemad mõtlejad uskusid, et Jumal toimib ja viib oma ettenägelikke plaane ellu loomulike põhjuste kaudu (Schechner Genuth 1997: 162, 189194).

W. Whiston püüdis kindlaks määrata ka aja, millal veeuputus aset leidis. Tema väitel ei ole Maa oma praeguses olekus olnud kauem kui 6000 või 7000 aastat ja suurest veeuputusest on möödunud vaevalt 5000 aastat (Whiston 1717: 142). E. Halley jälgedes käies väitis ta, et veeuputuse põhjustas ühe komeedi lähenemine Maale (vt Schechner Genuth 1997: 163-164, 190; Force 1985: 48). Tuginedes oma üsna täpsetele arvutustele väitis W. Whiston, et veeuputuse füüsikaliseks põhjuseks paistab olevat kuulus 1680/1. aasta komeet (Whiston 1717: $146 \mathrm{jj}$ ).

Meile võib see tunduda naeruväärne, aga 17. sajandi ja veel 18. sajandi alguse kosmoloogiates oli põrgu asukoht universumis tõsise arutelu objektiks. See, et põrgu on olemas ja et viimsel kohtupäeval süüdi mõistetud inimesed sinna satuvad, oli W. Whistonile täiesti loomulik ja mõistuspärane eeldus. Sest põrgu kui patuste piinamise paik on osa Jumala kui täiuslikult targa, võimsa ja õiglase vaimu plaanist inimese ja maailma suhtes. Kus asub põrgu? Tollased astronoomid võisid põrgu paigutada traditsiooniliselt Maa sisemus- 
se või ka mujale, näiteks Päikesele, nagu seda tegi aastal 1714 Tobias Swinden, kes lähtus koperniklikust universumimudelist (Almond 1994: 125 jj). Põrgu asukoha kindlaksmääramine eeldas nii teoloogilisi (eksegeetilisi) kui ka teaduslikke oskusi ja teadmisi, mis mõlemad olid W. Whistonil muidugi olemas.

Kõrvutades piibellikke põrgukirjeldusi teadusliku evidentsiga komeetide kohta ja vaadeldes kogu küsimust tõelise maailmasüsteemi valguses, tegi $\mathrm{W}$. Whiston loogilise teaduslik-teoloogilise järelduse:

Leian, et pühakirja kirjeldus põrgust ehk äraneetud inimeste karistamise paigast ja olukorrast pärast üldist ülestõusmist sobib kokku mitte üksnes antiikse profaanse traditsiooni ürikutega, vaid ka tõelise maailmasüsteemiga. Toda kurba olukorda kirjeldatakse pühakirjas kui pimeduse, kauge pimeduse, pilkase pimeduse seisundit, leegi või tule või tule ja väävliga piinamise ja karistamise seisundit, mis kestab ajast aega või igavesest ajast igavesti, kus on ulgumine ja hammaste kiristamine, kus jumalatute piinasuits tõuseb üles igavesest ajast igavesti, kus neid piinatakse pühade inglite ees ja talle ees, kus pühad inglid on eraldanud kurjad õigete keskelt ja visanud nad tuleahju.

See kirjeldus langeb nii täpselt üksikasjadeni kokku komeedi loomusega, komeedi, mis tõuseb üles kuumadest piirkondadest Päikese lähedal ja läheb külmadesse piirkondadesse Saturni taga ühes oma pika suitseva sabaga vastavalt oma tiirlemisperioodidele - ja seda kõigi ôhu ja ülejäänud maailmasüsteemi elanike nähes -, et ei jää üle muud kui arvata, et sä̈̈rase komeedi pind või atmosfäär ongi see piinamise koht, mida nii hirmuäratavalt kirjeldatakse pühakirjas, koht, kuhu oma lõplikuks hukatuseks või teiseks surmaks heidetakse Kurat ja tema inglid ühes äraneetud inimestega, kui nad on lahti päästetud vanglast Maa südames, ja Jumala ülejäänud mõistusega kreatuuridele saab see tõesti olema kohutav, aga ülimalt kasulik spektaakel, mis manitseb neid üle kõige säilitama oma sü̈̈tust ja kuulekust ja kartma teda, kes on võimeline hävitama põrgus nii hinge kui ka keha (Whiston 1717: $155 \mathrm{jj}$ ).

Niisiis paigutas W. Whiston selle hirmuäratava piinapaiga lõppkokkuvõttes komeedi pinnale või atmosfääri, kusjuures ühe versiooni järgi on siin taas tegemist Maaga, mille Jumal uuesti komeediks muudab. ${ }^{6}$ Võib öelda, et William Whistoni ideed on kujukaks näi- 


\section{Roomet Jakapi}

teks teadusliku ja religioosse mõtlemise tihedast seotusest ja põimumisest varasemal uusajal.

\section{Kommentaarid}

1 Täielik pealkiri A New Theory of the Earth, From its Original, to the Consummation of all Things. Wherein the Creation of the World in Six Days, the Universal Deluge, And the General Conflagration, As laid down in the Holy Scriptures, Are Shewn to be perfectly Agreeable to Reason and Philosophy.

2 Thomas Burneti teos Sacred Theory of the Earth ilmus 1690. aastal (arutelu selle vaidluse üle vt Force 1985: 2. ptk; Almond 1994: 127; Schechner Genuth 1997: 162 jj).

${ }^{3}$ Selles artiklis vaadeldakse eelkõige 17 . sajandi teise ja 18 . sajandi esimese poole mõttesuundumusi Inglismaal.

4 Üks paljudest huvitavatest aruteludest sel teemal sisaldub George Berkeley teoses Alciphron: Or, the Minute Philosopher (1732), VI dialoogi paragrahvides 21-23 (Berkeley, Works 3: 258-265).

5 Vt Israel 2001: 456-457, 461, 518-520.

${ }^{6}$ Kommentaare W. Whistoni põrgukäsitlusele vt Almond 1994: 128 jj; Schechner Genuth 1997: 193 jj.

\section{Kirjandus}

Almond, Philip C. 1994. Heaven and Hell in Enlightenment England. Cambridge \& New York: Cambridge University Press.

Berkeley, George 1948-1957. The Works of George Berkeley, Bishop of Cloyne 1-9. Luce, Arthur Aston \& Jessop, Thomas Edmund (toim). Bibliotheca Britannica philosophica. London \& Edinburgh et al.: Thomas Nelson and Sons.

Force, James E. 1985. William Whiston: Honest Newtonian. Cambridge et al.: Cambridge University Press.

Israel, Jonathan Irvine 2001. Radical Enlightenment: Philosophy and the Making of Modernity 1650-1750. Oxford: Oxford University Press.

Schechner Genuth, Sara 1997. Comets, Popular Culture, and the Birth of Modern Cosmology. Princeton (New Jersey): Princeton University Press.

Whiston, William 1717. Astronomical Principles of Religion, Natural and Reveal'd ... Together with a preface, of the temper of mind necessary for the discovery of divine truth, etc. (The Cause of the Deluge demonstrated). London. 